\title{
EN BUSCA DE LA BIOLOGÍA. REFLEXIONES SOBRE LA EVOLUCIÓN
}

\author{
Máximo Sandín \\ Universidad Autónoma de Madrid
}

\section{RESUMEN}

Después de 150 años de concebir y tratar a la Naturaleza en términos de competencia, costebeneficio, explotación de recursos, estrategias..., hemos conseguido que ésta entre en «recesión». Este alejamiento de la realidad, de los fenómenos naturales, ha puesto en grave peligro el futuro de la Humanidad sobre nuestro planeta y hace necesaria, incluso urgente, la búsqueda de una concepción de la Biología basada en conceptos y vocabulario científicos que nos vuelva a conectar con la Naturaleza antes de que sea demasiado tarde.

PALABRAS CLAVE: Evolución. Gen. Mercado. Información genética. Sistemas.

\section{IN SEARCH OF BIOLOGY. REFLECTIONS ON EVOLUTION}

\section{ABSTRACT}

After 150 years conceiving and dealing with Nature in terms of competence, costs-benefits, exploitation of resources, strategies..., we have managed to make it enter into a «recession». This estrangement from reality and from natural phenomena, has seriously jeopardized the future of mankind on our planet and makes it necessary, even urgent, the search for a conception of biology based on scientific concepts and vocabulary that re-connects us with Nature before it is too late.

KEY WORDS: Evolution. Gene. Market. Genetic information. Systems.

La naturaleza debe ser obligada a servir, reducida a la obediencia y esclavizada... para extraer, bajo tortura, todos sus secretos.

Francis Bacon (1561-1626)

\section{EN GUERRA CONTRA LA NATURALEZA}

Si intentamos encontrar una palabra que describa la relación de las sociedades autodenominadas «avanzadas» con la Naturaleza, esta sería 'miedo'. Y 
el miedo engendra agresividad. No se trata de una figura retórica. Nuestra sociedad vive entre el miedo y la prepotencia, unas actitudes en las que (hay que decirlo) ha habido una gran contribución por parte de los biólogos. Hay temor a los terribles virus: al virus del SIDA, al Ébola, al virus del Nilo y al de la gripe aviar, que surgen de las zonas más pobres de la Tierra para poner en peligro las vidas de los ciudadanos de los países desarrollados. Temor a las bacterias, que se esconden en los aparatos de aire acondicionado, en los hospitales, en alimentos y que se han hecho resistentes a nuestra arma más eficaz para luchar contra ellas, los antibióticos... Se diría que vivimos en una permanente campaña contra la Naturaleza dirigida hoy por biólogos que informan a la población de los ataques que recibimos y de las estrategias para luchar contra ella. En los medios de comunicación, los expertos nos hablan de los esfuerzos para luchar contra los distintos y abundantes «enemigos» que nos acechan, desde microscópicos hasta los, más visibles, mosquitos «asesinos» (una calificación abundantemente repartida por todo el «árbol filogenético», como bien se empeñan en difundir a la población desde los documentales sobre la vida «salvaje»). La crueldad de la Naturaleza impone un permanente estado de guerra. Contra la enfermedad, hasta contra la vejez. Pero los expertos nos informan de que antes o después conseguiremos derrotarla, dominarla, hasta el extremo de poder vivir al margen de sus leyes. Se conseguirá, «cambiando nuestros genes», o «limpiando los genomas de basura», alargar la vida (para algunos hasta la inmortalidad), «dirigir la evolución», crear «gente más inteligente y productiva», regenerar órganos o miembros, crear seres biónicos... unos objetivos que tienen mucho de fantasías infantiles (con poca reflexión sobre sus consecuencias, en el caso de que lo consiguieran) que parecen pretender reproducir las creaciones de los autores de los «superhéroes» de los cómics.

Pero cuando, en las revistas científicas, se publican estos planteamientos como prioridades en la investigación científica junto con resultados de investigaciones que ponen de manifiesto la enorme complejidad de la información genética y la imposibilidad de controlar realmente los procesos que pretenden manipular, se viene a la mente la angustiosa imagen del aprendiz de brujo. Porque aunque, afortunadamente, el futuro que proponen, un futuro Blade Runner, no es ni técnicamente posible ni ecológicamente viable, los riesgos para la Humanidad que se pueden producir por estos intentos son imprevisibles pero, a la vista de accidentes que ya se han producido, quizás no sea exagerado decir que sus consecuencias pueden ser de proporciones incalculables. 


\section{LA GRAN CONFUSIÓN}

Quizás sea conveniente apoyar con datos estos argumentos que pueden parecer excesivamente alarmistas, incluso «melodramáticos». Para ello, lo más clarificador puede ser recurrir a las revistas científicas generalistas, que tienen la ventaja sobre las revistas especializadas (habitualmente muy repetitivas y limitadas en los enfoques y en las interpretaciones) de abarcar distintos campos de las ciencias y ofrecer distintas perspectivas de cada una, lo que nos permite comparar el estado de los conocimientos alcanzados en las distintas ramas de la Biología.

El resultado de esta observación nos lleva a la alarmante sensación de que la Biología se encuentra en un estado de inconsistencia, se podría decir más, de absoluta ausencia de base teórica. Una situación que puede resultar peligrosa si tenemos en cuenta los procesos naturales que se manipulan para conseguir los objetivos antes mencionados. Porque la ausencia de un modelo teórico que proporcione sentido a estas manipulaciones viene siendo denunciada desde hace tiempo, de una forma esporádica $\mathrm{y}$, al parecer, sin la menor repercusión, desde las mismas revistas que mantienen en sus páginas esta confusión. Veamos algunos ejemplos: En 2001, con motivo de los progresos en la secuenciación del genoma humano y el los conocimientos sobre el proteoma (conjunto de proteínas que se expresan en la célula) P. Ball escribió en Nature:

«La Biología carece de un marco teórico para describir este tipo de situación (...) los biólogos van a tener que construir una nueva biología. Desde que en los años sesenta se descifró el código genético, la biología molecular ha sido una ciencia cualitativa, dedicada a investigar y clasificar las moléculas de la célula como los zoólogos victorianos catalogaban las especies. El genoma humano marca la culminación de ese esfuerzo. Ahora se necesitan modelos y teorías que ayuden a lograr que la inmensa fortuna de datos que se han amasado cobre sentido» ${ }^{1}$.

Incluso se ha llegado a cuestionar muy seriamente la concepción tradicional de la base teórica de la biología. En un alarde de reflexión sincera producido por el alegre suceso de la paternidad, Hery Gee, uno de los editorialistas de Nature, escribió algo sobre lo que merece la pena pensar:

«La cuestión del origen de las especies debe tener que ver, fundamentalmente, con la evolución de programas embrionarios (...) Usted puede buscar a Darwin para una respuesta pero buscará en vano. Darwin estudió leves variaciones en carac-

1 BALL, P. (2001), Ideas for a new biology, Nature science update, 12 de febrero. 
terísticas externas, sugiriendo cómo esas variaciones pueden ser favorecidas por circunstancias externas, y extrapoló el proceso al árbol completo de la vida. Pero, seguramente, hay cuestiones mas profundas para preguntarse que por qué las polillas tienen alas más negras o más blancas, o por qué las orquídeas tienen pétalos de esta u otra forma. ¿Por qué las polillas tienen alas y por qué las orquídeas tienen pétalos? ¿Qué creó esas estructuras por primera vez? La victoria del Darwinismo ha sido tan completa que es un shock darse cuenta de cuan vacía es realmente la visión Darwiniana de la vida»².

La única repercusión de semejante arrebato fue un largo período de desaparición de sus editoriales seguido de una vuelta a los análisis de los descubrimientos científicos con reflexiones menos conflictivas. Pero no se puede evitar que los científicos que se enfrentan con honestidad a la situación en que se encuentra la base teórica de la biología se expresen con claridad al respecto:

«La Biología hoy, está donde estaba la Física a principios del siglo veinte, observa José Onuchic, codirector del nuevo Centro de Física Biológica Teórica de la Universidad de California, San Diego. Se enfrenta a una gran cantidad de hechos que necesitan una explicación» ${ }^{3}$.

Efectivamente, esta complejidad de los fenómenos biológicos necesita una explicación. Y para no perdernos en la enorme cantidad de información sobre esta complejidad que han acumulado los distintos campos de la Biología (del desarrollo, ecológico, bioquímico...), puede ser ilustrativa una mirada sobre los procedentes del estudio del control de la información genética, porque se puede considerar el aspecto fundamental de la base teórica de la Biología.

Los últimos progresos en la comprensión de la actividad de los genomas han derribado toda una concepción sobre la naturaleza del los genes. El mejor resumen de este hecho es el que nos ofrece E. Pennisi desde la revista Science ${ }^{4}$.

«Los genes, piedra angular del desarrollo y funcionamiento de los organismos, no pueden explicar por sí solos qué hace a las vacas vacas y maíz al maíz. Los mismos genes se han manifestado en organismos tan diferentes como, digamos, ratón y medusa. Es más, nuevos hallazgos de una variedad de investigadores han

2 GEE, H. (2000), Of Goethe, genomes an how babies are made, Nature science update, 10 febrero.

3 Knight, J. (2002), Physics meets biology: Bridging the culture gap, Nature, 419, pp. 244-246.

4 Pennisi, E. (2004), Searching for the Genome's Second Code, Science, 306 (5696), pp. 632-635. 
puesto en claro que es el exquisito control por el genoma de la actividad de cada gen $-\mathrm{y}$ no los genes per se- lo que más importa».

Efectivamente, los resultados del Proyecto Encode (Encyclopedia of DNA Elements) que, mediante la cooperación de 35 grupos de trabajo, el uso de potentes métodos bioinformáticos, y estudiando la actividad de 44 regiones seleccionadas al azar que constituyen el 1\% del genoma codificante de proteínas ha obtenido «la mayor resolución obtenida hasta ahora», han puesto de manifiesto que

«los genes tienen muchas formas alternativas y un mismo gen puede dar lugar a proteínas distintas dependiendo de cómo se combinen las distintas regiones. Pero lo más determinante es cómo se controla esa información: Estas regiones del genoma analizadas están muy interconectadas unas con otras, mientras que la idea que tenían hasta el momento los científicos era que los genes estaban claramente delimitados. En el genoma, todo un conjunto de instrucciones dictan cómo son las características de los seres vivos. Los científicos no sabemos muy bien cómo leer esas instrucciones y qué regiones del genoma son las que realmente codifican esas instrucciones».

Pero sí se conoce, cada día con más certeza, donde están las más importantes.

«La mayor parte del genoma tiene actividad [se podría aventurar que la totalidad] es decir, no está «silencioso», lo que echa por tierra la idea de que una gran parte del ADN sería algo así como «basura», sin función alguna» ${ }^{5}$.

En efecto, entre toda la inmensa maraña que constituye el control de la información genética, ha surgido con una gran importancia (seguramente la fundamental) la actividad de lo que, gracias a la «aportación» de la llamada «teoría del gen egoísta», ha permanecido durante muchos años fuera del foco de interés de los genetistas 6 por su consideración de «ADN basura» (más concretamente «chatarra»). La fracción «no codificante» del genoma, que constituye el $98,5 \%$ de la totalidad del genoma, está formada por «ADN intergénico», es decir, intrones, virus endógenos, elementos móviles y una gran

5 Gerstein, M.K., Bruce, C., Rozowsky, J.S. et al. (2007), What is a gene, postENCODE? History and updated definition, Genome Res., 17, pp. 669-681.

6 Von Sternberg, R. (2002), On the Rules of Repetitive DNA Elements in the context of a Unified Genomic-Epigenetic System, Annals of the New York Academy of Sciences, 981, pp. 154-188. 
variedad de secuencias repetidas en mayor o menor medida entre las que se encuentran, por ejemplo, los «elementos ultraconservados» específicos de vertebrados, las LINE (long interpersed elements), las SINE (short interpersed elements) entre ellas, las ALU, elementos repetidos específicos de primates. En esta región del genoma se encuentra el sistema de control de la actividad de la fracción codificante, fundamentalmente, mediante los microARN, miles de moléculas de entre 21 y 25 nucleósidos cuyo origen está en las secuencias repetidas los elementos móviles y los virus endógenos ${ }^{7}$, pero también mediante la actividad de enhancers («potenciadores») ${ }^{8}$ y de intrones, implicados en el splicing alternativo ${ }^{9}$, mediante el cual, hasta el $95 \%$ de los genes humanos pueden generar distintos transcritos ${ }^{10}$. Todas estas actividades están condicionadas por el almacenamiento y procesamiento de información por parte del, por el momento, indescifrable proteoma ${ }^{11}$, y por el estado del metabolo$m a^{12}$, es decir, por las condiciones ambientales. Un ambiente, cuya influencia se muestra cada día más evidente en los fenómenos epigenéticos, cambios fenotípicos heredables (y reversibles) en la expresión génica que se producen sin un cambio en la secuencia del ADN, mediante la metilación del ADN, las modificaciones de cromatina o histonas y «saltos» de elementos móviles ${ }^{13}$.

7 SANDín, M. (2005), La transformación de la evolución, Boletín de la Real Sociedad Española de Historia Natural. Sección Biológica, 100, pp. 139-167.

8 PrabhaKar, S., Visel, A., et al. (2008), Human-Specific Gain of Function in a Developmental Enhancer, Science, 321 (5894), pp. 1346-1350.

9 Moran, J.V., Zimmerly, S., Eskes, R., Kennell, J.C. \& Lambowitz, A.M. (1995), Mobil group II introns of yeast mitochondrial DNA are novel site-specific retroelements, Molecular and Cellular Biology, 15 (5), pp. 2828-2838; Haugen, P., Simon, D.M. \& Bhattacharya, D. (2005), The natural history of group I introns, Trends in Genetics, 21 (2), pp. 111-119.

10 Pan, Q., Shai, O., Lee, L.J., Frey, B. \& Blencowe, B.J. (2008), Deep surveying of alternative splicing complexity in the human transcriptome by high-throughput sequencing, Nature Genetics, published online 2 November 2008, doi:10.1038/ng.259.

11 GAVIN, A.C. et al. (2002), Functional organization of the yeast proteome by systematic analysis of protein complexes, Nature, 415, pp. 141-147; Ho, Y., et al. (2002), Systematic identification of protein complexes in Saccharomyces cerevisiae by mass spectrometry, Nature, 415, pp. 180-183.

12 BARABÁsi, A.-L. \& OltVAi, Z.N. (2004), Network biology: understanding the cell's functional organization, Nature Reviews Genetics, 5, pp. 101-113; doi:10.1038/nrg1272.

13 BECKER, P.B. (2006), Gene regulation: A finger on the mark, Nature, 442, pp. 31-32; RICHARDS, E.J. (2006), Opinion: Inherited epigenetic variation - revisiting soft inheritance, Nature Reviews Genetics, 7, pp. 395-401; Slotkin, R.K. and MARTIENSSEN, R. (2007), Transposable elements and the epigenetic regulation of the genome, Nature Reviews Genetics, 8, pp. 272-285. 
En definitiva, y como una conclusión adicional que puede resultar simplificada, pero sobre la que tal vez merezca la pena pensar, el concepto de «unidad de información genética» no tiene una existencia real. Según Pearson «Cuanto más progresan nuestros conocimientos en bioquímica, más difícil es comprender qué es — si es que es algo- un gen ${ }^{14}$. Es decir, si una secuencia génica dañada se relaciona, por ejemplo con una enfermedad, esto no quiere decir que esa secuencia sea la responsable directa de esa enfermedad (y por eso es por lo que cada día se encuentran nuevos «genes del cáncer»), sino parte de todo un complejo «circuito» que relaciona distintos procesos, porque la información genética es el producto de una gran cantidad de interacciones de una extremada complejidad que está condicionada por el conjunto del genoma, al cual se podría considerar realmente como «unidad» de información. Y se puede llegar más lejos: si tenemos en cuenta que esta información está condicionada, a su vez, por el ambiente y este puede ser variable para cada individuo ¿Cuál sería entonces esta «unidad de información genética»? ¿Tal vez el organismo entero?

Pero volviendo al tema que nos ocupa, lo que resulta (o debería resultar) desconcertante para un biólogo es que, en la misma revista y, a veces en el mismo número, se publican investigaciones cuyas bases, argumentos y resultados son absolutamente contradictorios. Por ejemplo, sobre los fenómenos epigenéticos condicionados por el ambiente en las diferencias fenotípicas entre gemelos ${ }^{15}$ o sobre la enorme complejidad de las redes de información genética ${ }^{16}$ y sobre «el gen» de la infidelidad ${ }^{17}$, o del «gen» de los bebedores ${ }^{18}$. Sobre la inabarcable complejidad de las relaciones entre las proteínas celulares y sus actividades en función de sus agrupaciones ${ }^{19}$ y el descubrimiento de una proteína que controla todo un complejo proceso biológico ${ }^{20}$, sobre evo-

14 Pearson, H. (2006), Genetics: What is a gene?, Nature, 441, pp. 398-401.

15 Fraga, M.F., Ballestar, E., PaZ, M.F. et al. (2005), Epigenetic differences arise during the lifetime of monozygotic twins, PNAS, 102 (30), pp. 10604-10609.

16 SAuer, U., Heinemann, M. \& ZAMBOnI, N. (2007), Getting Closer to the Whole Picture, Science, 316 (5824), pp. 550-551.

17 Walum, H., Westberg, L., Henningsson, S. et al. (2008), Genetic variation in the vasopressin receptor 1a gene (AVPR1A) associates with pair-bonding behaviour in humans, PNAS, 105 (37), pp. 14153-14156.

18 Mulligan, M.K., Ponomarev, I., Hitzemann. R. et al. (2006), Toward understanding the genetics of alcohol drinking through transcriptome meta-analysis, PNAS, 103 (16), pp. 6368-6373.

19 GAVIN et al. (2002); Ho et al. (2002).

20 AGO, H., KANAOKA, Y., IRIKURA, D. et al. (2007), Crystal structure of a human membrane protein involved in cysteinyl leukotriene biosynthesis, Nature, 448, pp. 609-612. 
devo en los que se analizan los cambios evolutivos en relación con cambios en el programa de desarrollo ${ }^{21}$ y sobre genética de poblaciones que explica, supuestamente, la evolución como «un cambio en las frecuencias génicas» 22 . Sobre el carácter global de la información genética y su subordinación a las condiciones ambientales ${ }^{23}$, incluso de la dificultad (o imposiblidad) de definir «qué es un gen» ${ }^{24} \mathrm{y}$ del descubrimiento de «genes egoístas» ${ }^{25}$ o la patente de un virus modificado con «el gen» P53 para ser explotada por una importante empresa farmacéutica ${ }^{26}$.

Lo que se observa (con inquietud) es una absoluta discordancia entre los resultados reales, es decir verificables experimentalmente, de la llamada investigación «básica», o lo que es lo mismo, investigación científica, y los planteamientos necesarios para que sean posibles los objetivos de la llamada investigación «aplicada», es decir, la enfocada a fines comerciales. Sin embargo, la persistencia en seguir por un camino, cuyo final en un callejón sin salida está marcado de antemano, ha de tener una explicación. Y la única posible es la que nos sugiere la existencia en las revistas citadas de un apartado cuyos encabezamientos habrían resultado absurdos cuando la actividad de los científicos se concebía como una búsqueda del conocimiento: Negocios (Science), Una mirada al Mercado (Nature).

\section{LA Biología Y EL MERCADO}

Resulta una obviedad afirmar que, hoy en día, el Mercado (concretamente «el libre mercado») es el que determina el curso de las relaciones humanas, de la sociedad, en suma, el destino de la Humanidad. Quizás no parezca este el sitio o el contexto adecuado para discutir este modelo económico, Pero si tenemos en cuenta que, según los informes de la ONU, los mercados que más dinero «generan» en el Mundo son, por este orden, el de las armas, el de la

21 Hall, B.K. (2003), Evo-Devo: evolutionary developmental mechanisms, Int. J. Dev. Biol., 47, pp. 491-495.

22 StumpF, M.A. \& MCVEAn, G.A.T. (2003), Estimating recombination rates from population-genetic data, Nature Reviews Genetics, 4, pp. 959-968.

23 BARABÁsI \& OLTVAI (2004).

24 GERSTEIN et al. (2007).

25 EnserinK, M. (2007), Selfish Genes Could Help Disease-Free Mosquitoes Spread, Science, 315 (5820), pp. 1777-1778.

26 GuO, J., and XIN, H. (2006), Chinese Gene Therapy: Splicing Out the West?, Science, 314 (5803), pp. 1232-1235. 
droga, el del petróleo y el farmacéutico (U. N., 1999) ${ }^{27}$ tal vez encontremos una conexión con el problema que estamos analizando.

La confusión entre ciencia, es decir, la actividad dedicada a la búsqueda del conocimiento y tecnología (aplicaciones de los conocimientos obtenidos) y la concepción de la investigación científica como «una potente herramienta para el desarrollo y la competitividad», ha conducido a la Biología a una investigación dirigida por intereses comerciales, a una carrera por la búsqueda de «patentes» de «biofármacos», de «genes» y proteínas de interés económico y a un olvido de su verdadera esencia. El problema, el grave problema que deriva de esta actitud, es que se ha olvidado poner al día la base teórica que daría en contexto adecuado a estas investigaciones $\mathrm{y}$, a juzgar por los planteamiento y objetivos que hemos mencionado anteriormente, se trabaja como si los datos recientes derivados de la investigación básica no hubieran desmentido la obsoleta concepción reduccionista, competitiva y aleatoria de los fenómenos biológicos.

El origen de esta confluencia entre Biología y Mercado se encuentra en las raíces de la base teórica que ha conformado la visión de la Naturaleza en los últimos 150 años. Según Darwin (1859), su teoría «es la doctrina de Malthus aplicada con multiplicada fuerza al conjunto de los reinos animal y vegetal; porque en este caso, no hay aumento artificial de alimento y limitación prudente de matrimonios ${ }^{28}$. La doctrina a la que se refiere es la que el reverendo R.T. Malthus, como es sabido, discípulo de Adam Smith y uno de los padres de la economía liberal clásica, expone en Ensayo sobre el principio de la población ${ }^{29}$. Según Leon Harris

«El razonamiento de Malthus era que el progreso era imposible a menos que exista un abastecimiento ilimitado de alimentos, por lo que las políticas dirigidas a mejorar la situación de los pobres eran equivocadas (...) Los defensores del Laissez faire podría así ignorar a los niños hambrientos con la conciencia tranquila» ${ }^{30}$.

En definitiva, podríamos detectar las estrechas relaciones entre ambas «teorías»y los motivos de su implantación, recurriendo a pensadores muy cualificados que, al parecer, lo han visto con claridad: La obra de Darwin es,

27 UNITED NATIONS DRUG CONTROL PROGRAM, Report of the International Narcotics Control Board for 1999, E/INCB/1999/1 United Nations, Vienna 1999.

28 DARwIN, Ch. (1859), On the Origin of Species by Means of Natural Selection, or the Preservation of Favored Races in the Struggle for Life, London, John Murray.

29 Malthus, T.R. (1798), An Essay on the Principle of Population (Ensayo sobre el principio de la población, Editorial Claridad, 1997).

30 HARris, C.L. (1985), Evolución. Génesis y revelaciones, Madrid, Blume, p. 233. 
en palabras de Bertrand Russell «una extensión al mundo animal y vegetal de la economía de Laissez faire» ${ }^{31}$. Y para el filósofo de la ciencia R.M. Young «Lejos de ser un mecanismo en favor del cambio, era una defensa del status quo, tanto en la naturaleza como en las sociedades» ${ }^{32}$.

De hecho, en la que podemos considerar la versión mas «moderna» del darwinismo, la elaborada por Richard Dawkins ${ }^{33}$, su propuesta de lo que sería el motor de la evolución y de las relaciones entre los seres vivos es, sólo con un ligero cambio de estilo, una transcripción de la fórmula dieciochesca de Adam Smith para las relaciones sociales

«No es de la benevolencia del carnicero, cervecero o panadero de donde obtendremos nuestra cena, sino de su preocupación por sus propios intereses (...) Prefiriendo apoyar la actividad doméstica en vez de la foránea, sólo busca su propia seguridad, y dirigiendo esa actividad de forma que consiga el mayor valor, sólo busca su propia ganancia, y en este como en otros casos está conducido por una mano invisible que promueve un objetivo que no estaba en sus propósitos» ${ }^{34}$

con la simple sustitución de los términos cervecero o panadero por la palabra «gen» y la mano invisible del mercado por la mano invisible de la ciega pero todopoderosa selección natural. Y los términos «egoísmo», «competencia por los recursos», «estrategias», «coste-beneficio», «colonización»... son parte constituyente de la terminología $\mathrm{y}$, por tanto, de la interpretación de los fenómenos naturales de la Biología actual.

\section{LA SÍNTESIS MODERNA. UN PASO MÁS LEJOS DE LA NATURALEZA}

Una argumentación utilizada habitualmente para rebatir las críticas a las ideas darvinistas es que la teoría actual no es exactamente la original de Charles Darwin, sino la «Teoría Sintética Moderna», enriquecida con los conocimientos de la genética mendeliana. Veamos, pues, cómo se construyó la base teórica actual de la Biología.

31 Russell, B. (1935), Religión and Science, New York, Oxford Univ. Press, pp. 72-73.

32 Young, R.M. (1973), The historiographic and ideological contexts of the nineteenthcentury debate on man's place in nature. En TEICH, M. \& YounG, R.M., Changing perspectives in the history of Science, Boston, Reidel, p. 116.

33 Dawkins, R. (1975), The selfish Gene, Oxford University Press (El gen egoista, Barcelona, Salvat, 1993).

34 SMith, A. (1996), Investigación sobre la naturaleza y causas de la riqueza de las naciones, Méjico, Fondo de Cultura Económica (original 1776), pp. 26-27. 
A principios del siglo XX, los genetistas, basándose en sus observaciones sobre la aparición y la transmisión de las características heredables, y que se podían comprobar en los «experimentos» (pero esta es otra historia) de Mendel, habían desechado la idea de la evolución como consecuencia de la acumulación de pequeñas variaciones «imperceptibles». Así nos lo narra Ayala en su libro La teoría de la evolución:

«De acuerdo con De Vries (y también con otros genéticos de principios del siglo XX, como el inglés William Bateson) hay dos tipos de variaciones en los organismos: un tipo consiste en la variación «ordinaria» observada entre los individuos de una especie: por ejemplo, variación en el color de los ojos o las flores, o variación en el tamaño. Este tipo de variación no tiene consecuencias últimas en la evolución, porque, según De Vries, «no puede traspasar los límites de la especie, incluso bajo las condiciones de la más fuerte y continua selección». El otro tipo consiste en las variaciones que surgen por «mutación genética»; esto es, alteraciones espontáneas de los genes que ocasionan grandes modificaciones de los organismos y que pueden dar origen a nuevas especies: Una nueva especie se origina de repente, es producida a partir de una especie preexistente sin ninguna preparación visible y sin transición» ${ }^{35}$.

Estas ideas, que Ayala nos narra como una visión errónea, pero que estaban basadas en observaciones científicas reales y que, por tanto, estaban en el buen camino, fueron arrolladas por otras basadas, dentro de la tradición darvinista, en especulaciones y suposiciones sin la menor relación con los fenómenos que se producen en la Naturaleza, es decir, inventadas. Los «biometristas», darvinistas fervorosos encabezados por el matemático inglés Sir Karl Pearson, acudieron en ayuda de la selección natural actuando sobre variaciones que denominaron «métricas»o «cuantitativas».

Así nos narra Richard Milner el nacimiento de la base teórica del darwinismo actual: En medio del debate entre genetistas sobre la dilución de las pequeñas mutaciones individuales entre la población, R.C. Punnett, discípulo de Bateson,

«expuso el problema a su amigo G.H. Hardy, profesor de matemáticas en la Universidad de Cambridge, quien, según se dice, escribió la solución en el puño de la camisa mientras comía. Como la consideró muy elemental, Hardy se negó a presentarla en una publicación que normalmente leerían sus colegas matemáticos, por lo que Punnett la expuso en una revista de biología. Fue la única incursión de Hardy en

35 Ayala, F.J. (1999), La teoría de la evolución. De Darwin a los últimos avances de la genética, Madrid, Temas de Hoy, p. 37. 
la genética. [?] La solución obtenida por el profesor Hardy fue que la simple expresión binomial $(\mathrm{p} 2+2 \mathrm{pq}+\mathrm{q} 2)=1$ describe la proporción de cada genotipo en la población, donde $\mathrm{p}$ representa el alelo dominante $(\mathrm{A})$, $\mathrm{q}$ el recesivo $(\mathrm{a}) \mathrm{y}(\mathrm{p}+\mathrm{q}=1) »^{36}$.

El alejamiento de estas premisas de la realidad (que se acentúa con las absurdas condiciones que debe de cumplir la población implicada) ya era evidente por entonces. Según Harris «Haldane [otro matemático padre de la «síntesis»] era consciente de que existían fenómenos como el ligamiento que ya eran conocidos, pero tenerlos en cuenta hubiera complicado los cálculos» ${ }^{37}$.

Aquí me voy a permitir una pequeña digresión: Resulta pasmosa la naturalidad con que los historiadores autocalificados como firmes seguidores del darwinismo nos narran los artificios que han intervenido en su elaboración como teoría científica, porque resulta difícil de dilucidar si se trata del resultado de una fe poco menos que religiosa a la que los datos históricos no afecta o de una actitud cínica en el sentido de decir «es una falacia, pero es la falacia dominante».

Sin embargo, parece que, efectivamente, los matemáticos lograron convencer a algunos biólogos. Así relata Ayala la acogida inicial de la base teórica de la evolución:

«Estos descubrimientos [?] teóricos, sin embargo, tuvieron inicialmente un impacto limitado entre los biólogos contemporáneos, porque estaban formulados en ecuaciones y lenguaje matemáticos que la mayoría de los evolucionistas no podían entender [aquí me voy a permitir argumentar, a modo de «reparación» de estas dudas sobre la capacidad mental de mis colegas, que resulta dudoso que no entendieran unas fórmulas basadas en algo tan simple como las probabilidades de obtener cara o cruz en una moneda lanzada al aire, es decir, que tal vez fue otro el motivo de su rechazo]; también, debido a que estos descubrimientos, casi exclusivamente teóricos [?] tenían poca corroboración empírica, y, por último, a causa de que los problemas resueltos habían dejado de lado muchas otras materias de gran interés,

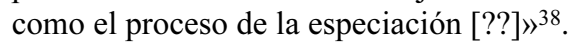

Pero el problema que planteaban los biólogos estaba superado. Según E. Mayr: «Los matemáticos demostraron convincentemente que, incluso mutaciones con ventajas relativamente pequeñas, eran favorecidas por la selección, y sus hallazgos ayudaron a superar varias objeciones a la selección natura» ${ }^{39}$.

36 MiLner, R. (1995), Diccionario de la evolución, Barcelona, Bibliograf, p. 318.

37 HARRIS (1985), p. 292.

38 AYAla (1999), p. 39.

39 MAYR, E. (1997), The establishment of evolutionary biology as a discrete biological discipline, BioEssays, 19 (3), pp. 263-266. 
En cualquier caso, ya estaba «demostrada» mediante las matemáticas la actuación de la selección natural como el mecanismo evolutivo. La sentencia (¿de muerte?) sobre el estudio de la evolución la emitió T. Dobzhansky: «La Evolución es un cambio en la composición genética de las poblaciones. El estudio de los mecanismos de evolución es competencia de la Genética de Poblaciones $\rangle^{40}$. Y desde ese momento, la base teórica de la Biología, pasó de apoyarse en los conocimientos y en los criterios científicos utilizados hasta entonces, basados en la elaboración de deducciones obtenidas a partir de la observación de los fenómenos naturales, a la interpretación de la Naturaleza en función de la práctica tradicional en el darwinismo, es decir, a adecuar las observaciones a la teoría, (en este caso ni siquiera observaciones, sino suposiciones), mediante fórmulas matemáticas.

Y este «olvido» de las observaciones de la Naturaleza, de los organismos, del registro fósil, para crear una explicación elaborada sobre cálculos numéricos basados en hipótesis al margen de la realidad, lleva a una total desconexión de la realidad. Así explica Ayala el concepto actual de la evolución según estos criterios:

«El rango de una mutación génica puede ir, pues, de inapreciable a letal (...) las mutaciones nuevas tienen mayor posibilidad de ser perjudiciales que beneficiosas para los organismos. Una nueva mutación es posible que haya sido precedida de una mutación idéntica en la historia previa de una especie. Si esa mutación previa no existe en la población, lo más probable es que no sea beneficiosa para el organismo y, por ello, será eliminada de nuevo (...) El proceso de mutación cambia las frecuencias génicas muy lentamente debido a que las tasas de mutación son bajas (...) Si en un momento dado la frecuencia del alelo $\mathrm{A}$ es 0,10 , en la generación siguiente se habrá reducido a 0,0999999, un cambio evidentemente pequeñísimo (...) Por otra parte, las mutaciones son reversibles: el alelo B puede también convertirse en alelo A (...) Aunque las tasas de mutación son bajas si se considera un gen individualmente, el hecho de que haya muchos genes en cada individuo y muchos individuos en cada especie hace que el número total de mutaciones sea elevado» ${ }^{41}$.

Como reflexión, seguramente discutible, y a modo de conclusión de este apartado, tengo que decir que la forma en que nació el darwinismo, la manera en que se ha narrado su historia, el modo en que se ha mantenido mediante artificios al margen de la realidad y la mitificación (¿mixtificación?) de la

40 Dobzhansky, T.H. (1951), Genetics and the origin of species, New York, Columbia University Press, p. 18.

41 Cela Conde, C.J. \& Ayala, F.J. (2001), Senderos de la evolución humana, Madrid, Alianza, pp. 45-57. 
figura de Darwin, produce la sensación (al menos, la sospecha) de que el problema no es de índole meramente científica. Y un posible apoyo a esta sensación se puede encontrar en el siguiente hecho: En 2006, es decir, cuando ya se había secuenciado el genoma humano, cuando ya eran sobradamente conocidos los fenómenos de splicing alternativo, los procesos epigenéticos, la naturaleza dispersa y fragmentaria de la información genética, se reunieron en la Universidad de Cambridge un grupo de prestigiosos investigadores que llegaron a la siguiente conclusión:

«Many regard the Darwinian theory of evolution by natural selection as one of the most important and powerful theories of our times, in the good company of the general theory of relativity and quantum theory. What will be Darwin's legacy in the 21 st century? Will new work be mainly confirmatory, or can we expect new breakthroughs? What constitutes a Darwinian way of thinking in biology, or more broadly in science? Is it still timely to think in a genuine Darwinian way, or should we resort only to some basic Darwinian principles? These questions were discussed by researchers at a recent conference at Trinity College, Cambridge, UK, which was hosted by the president of the Royal Society, Martin Rees.

There was fair agreement among the participants that Darwin's way of approaching problems remains valid and should be encouraged if possible» ${ }^{42}$.

\section{CONSTRUYENDO UNA BASE TEÓRICA COHERENTE}

La elaboración, o la propuesta de un modelo teórico capaz de interrelacionar de un modo coherente los datos procedentes del registro fósil con los conocimientos biológicos de que disponemos en la actualidad y de estos entre sí, ha de partir, necesariamente, de los datos actuales (y no a la inversa, como parece ser lo asumido). Pero antes de pasar a comentar (obligatoriamente, de un modo superficial) las principales características y el posible significado de esta propuesta ${ }^{43}$, creo conveniente un preámbulo para hacer unas aclaraciones sobre algunas confusiones, muy arraigadas en la terminología evolutiva, creadas precisamente por la confusión con que está planteado el darwinismo, tanto en su formulación inicial, como, muy especialmente, en sus posteriores «interpretaciones».

Este problema resulta, para un biólogo, muy arduo de analizar, pero no sólo por la confusión antes mencionada, sino porque hay concepciones tan asumidas que parece inconcebible dudar de ellas y sólo lo puede hacer el que

42 Szathmáry, E. (2006), Darwin for All Seasons, Science, 313 (5785), pp. 306-307.

43 SANDín, M. (1997), Teoría Sintética: Crisis y Revolución, Arbor, 623-624, pp. 269-303. 
está movido pos «intenciones ocultas». Unas sospechas que resultan absurdas, porque, precisamente, la práctica científica fundamental es buscar los puntos débiles de las teorías vigentes para mejorarlas o, en su caso, cambiarlas. Veamos, pues, algunos de ellos.

Quizás el concepto que, desde mi punto de vista, genera más confusión, porque de él derivan otras arrastradas por las simplificaciones de la teoría convencional es confundir «el origen de las especies» con la evolución. Esto parece tan arraigado que, incluso muchos científicos críticos con el darwinismo hablan de la evolución en estos términos. No quisiera parecer innecesariamente «pedagógico» para muchos, pero sí parece necesario repetirlo para algunos: El origen de las especies, que era de lo que (suponía que) hablaba Darwin, es la especiación (cuyas únicas evidencias experimentales es decir, no mediante cálculos matemáticos, indican que están implicados «saltos» de elementos móviles ${ }^{44}$ que hacen posible que el cambio se produzca simultáneamente en un número considerable de individuos. Según nos revela el registro fósil, las especiaciones se han producido infinidad de veces en los distintos taxones (tras los grandes cambios de organización) sin dejar de ser unas diversificaciones dentro de un patrón morfológico básico, pero no son el supuesto «inicio» de los cambios de organización, porque las diferentes especies que surgen así se mantienen sin cambios sustanciales en su organización durante toda su existencia. Repito mis excusas (y el ejemplo), pero las libélulas han sufrido cientos, tal vez miles de especiaciones desde su «aparición» en el Carbonífero, sin dejar de ser libélulas. Es decir, cuando hablamos de, o «demostramos» la especiación, no estamos hablando de evolución, sino de variabilidad dentro de un patrón morfológico.

Otra confusión arrastrada por la anterior y que, a su vez, la «retroalimenta», es la identificación de adaptación con evolución (la evolución como un proceso de adaptación gradual al ambiente), por ejemplo «los mosquitos evolucionan haciéndose resistentes a los insecticidas $\rangle^{45}$. Ya sabemos que existe una variada gama de procesos biológicos mediante los que los organismos responden a las condiciones de su entorno, es decir, mediante los cuales se ajustan, «se aferran» al ambiente. Esto no puede ser un mecanismo de cambio evolutivo sino, en todo caso, lo contrario. Los «mecanismos» de ajuste al ambiente son totalmente

44 Bergman, C.M. \& BeNSASSON. D. (2007), Recent LTR retrotransposon insertion contrasts with waves of non-LTR insertion since speciation in Drosophila melanogaster, PNAS, 104 (27), pp. 11340-11345; WESSLER, S.R. (2006). Transposable elements and the evolution of eukaryotic genomes, PNAS, 103 (47), pp. 17600-17601.

45 Ayala (1999), p. 120. 
diferentes en sus procesos y en su significado de los que producen los cambios de organización, aunque éstos también estén desencadenados, en última instancia, por alteraciones en las condiciones ambientales.

Pero quizás, lo que resulta más desalentador para el intento de depurar los conceptos científicos que se utilizan para describir procesos biológicos, algunos de una importancia verdaderamente trascendental, es la terminología derivada de la concepción de la Naturaleza de la «vieja» visión: las calificaciones que reciben todo tipo de fenómenos muy significativos, con expresiones que van desde términos empresariales hasta bélicos, pasando por el mundo del «hampa». Desde «carreras armamentísticas» hasta «explotación» de los virus endógenos por parte del genoma, pasando por calificaciones para éstos como «secuestradores», «saboteadores» o «falsificadores», por no hablar de las estrategias «egoístas» de los genes. No me cansaré de insistir en que esta no es una terminología científica, sino el producto de una concepción de la vida que podríamos calificar de patológica, que es utilizada para adecuar los datos a la teoría dominante, pero que lo que consigue es introducir graves distorsiones en la interpretación de los fenómenos biológicos y que resulta muy perjudicial para una verdadera comprensión de los fenómenos de reciente descubrimiento.

Consideraciones como estas, y algunas más vistas anteriormente, convierten en poco razonable la propuesta que, ante el aluvión de datos que contradicen radicalmente las asunciones asumidas sobre la evolución, han planteado algunos científicos ${ }^{46}$ : la de «expandir» la teoría darwinista. Por lo que he podido ver, esta idea parte, al parecer, de dos asunciones que pueden ir unidas o independientes: de que Darwin fue el «descubridor» de la evolución, por lo que cuando se habla de evolución se habla de darwinismo, o bien, que ya hay aspectos de la teoría darwinista que están «suficientemente demostrados». No parece necesario volver sobre la primera, pero sí puede ser conveniente insistir en que si la base teórica sobre la que se sustenta el darwinismo, la «Síntesis moderna», es absolutamente falsa, todos los conceptos que se elaboren a partir de ella también lo serán. Las únicas «demostraciones» de fenómenos visibles en la Naturaleza que todavía se ofrecen en los textos darwinistas como ejemplos de la evolución por selección natural siguen siendo el «experimento» de la polilla del abedul, el caso de la anemia falciforme, cuya manifestación se ha mostrado mucho más compleja de lo que se creía ${ }^{47}$ y la

46 CARroll, R.L. (2000), Towards a new evolutionary synthesis, TREE, 15 (1), pp. 27-32.

47 Higgs, D.R.; Wood, W.G. (2008), Genetic complexity in sickle cell disease, PNAS, 105 (33), pp. 11595-11596. 
adquisición de resistencia de los mosquitos a los insecticidas. El resto de las supuestas demostraciones son, simplemente, interpretaciones a posteriori sobre porqué esos fenómenos están ahí («porque han sido seleccionados»).

Parece razonable insistir en que ante la «aparición» de fenómenos y procesos inimaginables hace pocos años en el campo de la Biología, es necesario «repensar» la evolución y, por tanto las explicaciones de dichos procesos y su integración coherente en nuestra disciplina. En palabras de Mauricio Abdalla:

«La tecnología amplía la capacidad de «ver» fenómenos que antes estaban ocultos a los sentidos humanos y, la mayoría de las ocasiones, abre un nuevo campo fenomenológico que impulsa a la ciencia a reajustarse, produciendo un movimiento en las teorías científicas y hasta crisis de paradigmas» ${ }^{48}$.

Lo que no parece razonable es la actitud de indignación con que es recibido por prestigiosos biólogos, como si fuera una agresión, cualquier intento de este tipo. Resulta envidiable el entusiasmo con que, por ejemplo, los físicos, reciben la existencia de cualquier punto débil en sus teorías o cualquier avance tecnológico que les permita profundizar en ellas o, incluso cambiarlas (y no se puede decir que no estén «actualizados» al respecto). También es cierto que ellos no disponen de un ser «providencial» que les trajo una verdad inmutable, porque todavía ninguno de sus grandes pensadores la ha encontrado. Tal vez por eso tampoco disponen de un aniversario con que celebrar el «verdadero nacimiento» de su disciplina. Ni siquiera el de Newton, porque sus explicaciones eran, de algún modo válidas, pero incompletas. Posiblemente, para encontrar un paralelo tendrían que remontarse a Aristóteles. Su teoría sobre el movimiento de «los cuatro elementos» hacia «sus semejantes»: el agua hacia el agua, la tierra hacia la tierra, el fuego hacia el fuego y el aire hacia el aire, explicaba todo. Era «evidente», incluso verificable experimentalmente. Todo el mundo podía comprenderla, pero no era una explicación real. Porque, en Ciencia (excepto, al parecer, para la Biología), ninguna explicación de un fenómeno complejo puede ser sencilla.

\section{SOBRE LA «INTEGRACIÓN DE SISTEMAS COMPLEJOS»}

Las críticas a las simplificaciones del darwinismo han existido desde su origen, tanto desde el punto de vista científico como por su condición ideoló-

48 Abdalla, M. (2006), La crisis latente del darwinismo, Asclepio, LVIII (1), pp. 43-94. 
gica. Pero en los últimos años la acumulación de información, tanto del registro fósil, cada día más conocido, como de los fenómenos desvelados por la capacidad de observación de que nos han dotado los progresos en la tecnología han añadido una verdadera multitud de datos reales, verificables, para apoyar estas críticas, y han conducido a algunos científicos a proponer la necesidad de un nuevo modelo evolutivo. Como creo que podría parecer una insolencia (y posiblemente lo sea) hacer una crítica de propuestas alternativas procedentes de científicos infinitamente más conocidos y prestigiosos que el que esto escribe, y también puede parecer injusto (y quizás también lo sea) criticar intentos realizados con honestidad y la mejor intención, quisiera justificar lo que sigue con el siguiente argumento: las alternativas que no estén sólidamente apoyadas en datos reales pueden contribuir a aumentar la confusión y son más susceptibles de descalificación por parte de los defensores de la teoría dominante. Por lo tanto, me limitaré a algunas sugerencias sobre las deficiencias que, en mi opinión (es decir, totalmente discutible), presentan como descripción de fenómenos biológicos reales o como explicaciones del proceso evolutivo y que tal vez podrían ser solventadas con una puesta en común si se contrastasen entre sí: Unos se presentan como modelos puramente abstractos, que de algún modo describen la complejidad de los fenómenos naturales pero sin referirse a datos o experimentos biológicos concretos. Otros, siguen la tradición darvinista contraponiendo a los argumentos retóricos que la apoyan otros, también de tipo retórico, es decir, discutiendo conceptos o creando otros supuestamente nuevos pero, igualmente, sin datos experimentales que los sustenten. La mayoría comparten muchas de las confusiones que hemos mencionado en el apartado anterior y, finalmente, algunos cuyas propuestas tienden a alejarse de la corriente convencional, prudentemente (y seguro que con sobrados motivos), no se atreven a dar el peligroso paso de «abjurar» del darwinismo (es decir, son alternativas «parciales») ante el riesgo de perder, posiblemente entre otras cosas, su reconocimiento profesional. En el caso de que esta sea la causa, como no se puede perder lo que, al parecer, no se tiene, me he podido permitir dar este peligroso paso.

Antes de volver a exponer, una vez más, los argumentos generales de esta propuesta, (de este «esbozo» de propuesta), quisiera insistir, también una vez más, en que creo sinceramente que nadie se puede considerar propietario de una idea científica. En primer lugar porque las ideas no tienen dueño, y menos las científicas que, en su origen eran para compartir y debatir con toda la comunidad científica y para beneficio de toda la Humanidad. Pero, en segundo lugar, porque todas las ideas científicas, incluidas las que puedan parecer más originales, están basadas en el trabajo de otros, contemporáneos o ante- 
cesores, sin el cual no se podrían haber formulado. No se podrían haber planteado las preguntas ni imaginado las respuestas. Y seguramente, así ha sido desde que la Ciencia existe como tal. Sólo se pueden considerar «teorías» originales cuando son «ocurrencias», sin base científica y, por tanto sin ideas u observaciones científicas sobre las que apoyarse, como la idea de que los «genes» son egoístas y competitivos, o que la Naturaleza selecciona los seres vivos de la misma forma que los ganaderos seleccionan ganado. Lo que he pretendido plantear es el bosquejo de un trabajo que, tampoco me cansaré de insistir, debería ser afrontado por equipos formados por especialistas de las distintas disciplinas, el de poner en común la enorme masa de información acumulada en los últimos años para elaborar una verdadera base teórica que relacionase todos ellos coherentemente, científicamente, pero sin olvidar muchas de las brillantes propuestas de científicos que nos han precedido y que pueden proporcionar el soporte para esa tarea. Una labor que, en este caso se apoya sobre los hombros de Lamarck, con su visión vitalista de la Naturaleza retomada por Steele y Jablonka, Arrhenius, con su idea de la panspermia retomada por Hoyle, Merezkovsky, y la simbiogénesis retomada por Margulis, Goldschmidt con sus «monstruos esperanzados» y el saltacionismo del proceso de especiación retomado por Gould y Eldredge. El problema de esta «protopropuesta», que asumo sin ambages, es que, cuando a las inevitables limitaciones de afrontar esta labor de una forma individual se unen las limitaciones personales, la visión que se obtiene es posiblemente superficial y seguramente incompleta.

No voy a repetir aquí los argumentos y contraargumentos y las referencias bibliográficas que ya han sido expuestas en otras ocasiones, a veces, en exce$\mathrm{so}^{49}$. Lo que propongo en este caso es una reflexión sobre el significado de los datos y fenómenos reales, científicamente verificables, que ya hemos expuesto y sus posibles implicaciones en los problemas planteados inicialmente.

Comencemos por el principio, es decir, por el origen de la vida en la Tierra, que se puede admitir como el hecho de mayor calado y el más significativo para la comprensión de la vida. Los datos de que disponemos (insisto: datos reales), son los de la existencia de bacterias, es más, de comunidades bacterianas con toda su complejidad ${ }^{50}$, incluso antes de que la Tierra acabase de formarse. Y aquí me permito llamar la atención sobre otra confusión: Todos los conceptos relativos al origen de la vida como un proceso gradual y al azar, muchos de los cuales figuran en textos científicos como algo «científi-

49 Véase SANDÍN (2005).

50 Allwood, A.C., Malcolm R.W., et al. (2006), Stromatolite reef from the Early Archaean era of Australia, Nature, 441, pp. 714-718; doi:10.1038/nature04764. 
camente demostrado» (la «sopa prebiótica», el «mundo ARN», LUCA, Urbilateria, por no hablar de los «replicadores» del «Gen egoísta»), son (¿sorprendentemente?) inventados. Se trata de hipótesis emitidas por sus autores como «una posibilidad», sin ninguna base empírica («cómo ha debido de ser»), pero que, con el tiempo y la necesidad de una explicación, han pasado a ser confusamente consideradas como reales. ¿No resulta desasosegante para un científico pensar que la base científica de su disciplina se sustenta sobre hechos inexistentes?

Volvamos, pues, a las bacterias. Los datos que se han obtenido de las rocas más antiguas de la Tierra muestran «ecosistemas bacterianos complejos». Esto, junto con consideraciones sobre la inviabilidad ecológica de la existencia de un solo tipo de bacteria ${ }^{51}$, hace pensar que tuvieron que «aparecer» así en la Tierra. Desde luego, las sorprendente y difícilmente explicables capacidades de las bacterias como «adaptaciones al azar», su capacidad para vivir en los hábitats más extremos e inadecuados para la vida (se podría decir, innecesarios), desde el interior de rocas hasta fumarolas submarinas, desde el interior de reactores nucleares hasta estériles salinas, y su capacidad para «adaptarse» a condiciones «artificiales» a las que jamás han estado expuestas en la Naturaleza hace esta explicación insostenible desde el punto de vista convencional. Su inexplicable abanico de nutrientes, desde sustancias industriales tóxicas hasta minerales escasos como titanio, les convierte en algo «especial» dentro de los seres vivos. Pero esta condición especial se acentúa si tenemos en cuenta que su actividad hizo posible la existencia de condiciones atmosféricas adecuadas para la existencia de la vida. Y aún más: «hicieron» la vida. La agregación de bacterias como base de la mayoría (es decir, no todas) de las estructuras de la célula eucariota es un hecho comprobado, tanto desde el punto de vista morfológico como genético. Otro aspecto de las bacterias que merece una atención especial es el referente a los llamados «biofilms». Su agrupación por millones de individuos, a veces de tipos diferentes, y sus espectaculares respuestas coordinadas a distintas alteraciones o estímulos del medio han llevado a la afirmación de que es un comportamiento inteligente $^{52}$ resultado de su «evolución» (otra confusión derivada de la vieja

51 Guerrero, R. Piqueras, M. y Berlanga, M. (2002), Microbial mats and the search for minimal ecosystems, Int Microbiol, 5, pp. 177-188.

52 WebB, J.S., Givskov, M. \& KJelleberG. S. (2003), Bacterial biofilms: prokaryotic adventures in multicellularity, Current Opinion in Microbiology, 6, pp. 578-585; BEN JACOB, E., Aharonov, Y. \& ASPIRA, Y. (2005), Bacteria harnessing complexity, Biofilms, 1, pp. 239-263; SHAPIRO, J.A. (2007), Bacteria are small but not stupid: cognition, natural genetic engineering and socio-bacteriology, Stud. Hist. Phil. Biol. \& Biomed. Sci., 38, pp. 807-819. 
noción que identifica evolución con «cambio en los genes» que lleva a hablar de «la evolución de las bacterias» o incluso «la evolución de los virus»). Habría que pensar si lo que realmente indica es que la inteligencia es una «propiedad emergente» de las interacciones coordinadas entre células, como demuestran las respuestas «coherentes» de «genes», proteínas, tejidos y órganos en el funcionamiento de los organismos. Y también que, muy probablemente ha podido ser así desde el principio de su existencia en la Tierra ${ }^{53}$. La enorme cantidad de bacterias en la Tierra (vivimos literalmente inmersos en un mar de bacterias), su condición de imprescindibles para el origen de la vida y para el funcionamiento de la vida misma en el interior y el exterior de los animales, colaborando a la fijación de nitrógeno en las plantas, a las que hicieron posible la colonización del medio terrestre, (una hipótesis que se ha podido comprobar al constatar cómo, tras la retirada del hielo en un glaciar de los Andes, las cianobacterias han creado las condiciones, mediante la fijación de nitrógeno, para la colonización del estéril suelo por las plantas, http://www.colorado.edu/news/r/578683be8d85cd4b9dff12272a0f6e8d.html (20/08/2009)), han hecho replantearse, por fin, su consideración de «microorganismos patógenos», y llegar a la conclusión (confiemos en que sea así) de que su carácter patógeno, extraordinariamente minoritario en relación con el número de tipos de bacterias conocidas, y mucho más con el, aún mayor de desconocidas ${ }^{54}$ se produce cuando alguna «agresión» desestabiliza sus condiciones naturales. Hay que decir que no se puede culpar a los científicos de la consideración inicial de las bacterias como agentes exclusivamente patógenos, ya que su descubrimiento tuvo lugar, precisamente, porque producían enfermedades lo que conducía a esa conclusión lógica. Lo que resulta menos disculpable es que la concepción de la naturaleza como un campo de batalla en el que todos son competidores ha conducido a aumentar las «desestabilizaciones» de las condiciones naturales de la bacterias hasta el extremo de que su reconocimiento como elementos «positivos» de la Naturaleza (no suficientemente divulgado y todavía no reconocido por muchos, especialmente en el campo de la medicina), tal vez llegue demasiado tarde. El alarmante aumento de la resistencia de las bacterias «patogenizadas» a los antibióticos, producida por el uso desmedido de éstos como medio de acabar con nuestros «enemigos», se está convirtiendo en un grave problema cuyas repercusiones finales ignoramos. Pero recientemente, se ha comprobado (quizás también demasiado tarde) que

53 Allwood et al. (2006).

54 LozUpone, C.A. and KNIGHT, R. (2007), Global patterns in bacterial diversity, PNAS, 104 (27), pp. 11436-11440. 
los antibióticos no son «competidores» de las bacterias, sino señales utilizadas por ellas para el control poblacional ${ }^{55}$ y en grandes dosis (en dosis anormales) son letales, es decir, no son «armas» para la lucha contra las bacterias. Son un componente más de la red de relaciones que une a todos los seres vivos.

Pero, en el imaginario popular y, al parecer, también en el de la mayor parte de los científicos, hay otros «peligrosos enemigos» (como sabemos, determinadas concepciones de «la realidad» necesitan enemigos para justificarse), que han sustituido a las bacterias en las acusaciones de todo tipo de males: los virus. Vamos a olvidarnos de las rocambolescas explicaciones sobre su origen en términos de «ADN egoísta» fugado de las células eucariotas mediante una cápsida fabricada ingeniosamente por estos a partir de genes inexistentes en las células, porque si esta explicación ya era pura ciencia ficción en su origen, con los datos actuales se convierte en simplemente, absurda. La inimaginable cantidad y variedad de virus (especialmente «fagos») desconocidos en su mayor parte (se asume que sólo se conoce un 10\% de los existentes, pero es posible que sean menos), la gran cantidad de «genes» no identificados con anterioridad en ningún organismo encontrados en los virus, cuya función es desconocida y que se ha estimado en un $80 \%$ del número de genes virales identificados ${ }^{56}$, la existencia de «fagos» simultáneamente con las primeras arqueas $^{57}$, y las especialísimas características de los virus, que en estado libre son inertes, hacen poco probable la idea convencional de su «evolución»a partir de un antecesor común y mucho menos de un origen celular. De hecho,

«la existencia de características específicas de los virus, como algunas proteínas de las envolturas, genomas en forma de ARN y ARN polimerasas especiales, sugiere, por el contrario, que al menos una parte de los virus no tiene el mismo origen celular que sus células huésped (...) La notable variedad de los virus y su relativa simplicidad sugieren un origen polifilético: diferentes grupos de virus habrían derivado independientemente a partir de diferentes orígenes $\rangle^{58}$.

Es decir, cabe la posibilidad, fuertemente apoyada por los datos, de que los virus «aparecieran» en la Tierra del mismo modo (y, posiblemente, al mismo tiempo) que las bacterias. Dejaremos para más adelante la discusión sobre el

55 DAVIES, J. (2006), Are antibiotics naturally antibiotics?, Journal Ind. Microbiol. Biotechnology, 33, pp. 496-499.

56 Villarreal, L.P. (2004), Viruses and the Evolution of Life, Washington, ASM Press.

57 WoESE, C.R. (2002), On the evolution of cells, PNAS, 99 (13), pp. 8742-8747.

58 ZILliG, W. \& ARNOLD, H.P. (1999), Sur la piste des virus primordiaux, La Recherche, 317, pp. 26-29. 
significado y la verosimilitud de esta posibilidad, para centrarnos en los datos que nos hablan de su implicación en la evolución de la vida sobre la Tierra.

Su consideración de «agentes infecciosos», con el mismo origen que la de las bacterias, es decir, condicionada por su «puesta en escena» en la Biología, ha conducido a calificar a los «fagos» como «virus que infectan a las bacterias». En realidad, se ha comprobado que son vehículos de intercambio de información entre ellas ${ }^{59}$ y precursores de los plásmidos, también esenciales en este fenómeno. Pero los virus en general también han sido esenciales en otro de mayor significado: cuando, anteriormente, mencionaba que la fusión de bacterias era responsable de «la mayoría» de las características de la célula eucariota, lo que pretendía indicar es que existe una considerable cantidad de complejos procesos y moléculas específicos de la célula eucariota que no proceden de las bacterias y que son, necesariamente, de procedencia viral. Muchos relacionados con la información genética, como mRNAs, cromosomas lineales y la separación de la transcripción de la translación ${ }^{60}$, polimerasas ${ }^{61}$, intrones ${ }^{62}$, telómeros y telomerasas ${ }^{63}$ o con procesos relacionados con la división celular como la meiosis ${ }^{64}$ o de las proteínas mitocondriales de replicación y transcripción ${ }^{65}$ pero también muchas moléculas, especialmente proteínas y enzimas, no existentes en las procariotas. La lista es ingente y hace referencia a proteínas, tanto codificadas por virus, como procedentes de sus cápsidas (glicosiltransferasas, priones, sincitinas) y ha sido ampliamente documentada con anterioridad (ver «La transformación de la evolución»), aunque, como se aclaraba en dicha exposición esta documentación se ha realizado, en la mayoría de los casos, en base a los datos expuestos en los distintos trabajos, pero no en las interpretaciones de su presencia habitualmente basadas en la concepción del ADN

59 BEN JACOB et al. (2005).

60 Bell, P.J. (2001), Viral eukaryogenesis: was the ancestor of the nucleus a complex DNA virus?, Journal of Molecular Evolution, 53 (3), pp. 251-256.

61 Villareal, L.P. \& DE FilipPis, V.R. (2000), A Hypothesisi for DNA Viruses as the Origin of Eukaryotic Replication Proteins, Journal of Virology, 74 (15), pp. 7079-7084.

62 Fedorov, A., Roy, S., Fedorova, L. \& Gilbert, W. (2003), Mystery of Intron Gain, Genome Research, 13, pp. 2236-2241.

63 Schawalder, J., PARic, E. \& NefF, N.F. (2003), Telomere and ribosomal DNA repeats are chromosomal target of the bloom syndrome DNA helicase, BioMed Central Cell Biology, 4, 11.

${ }^{64}$ Bell, P.J. (2006), Sex and the eukaryotic cell cycle is consistent with a viral ancestry for the eukaryotic nucleus, Journal of Theoretical Biology, 243 (1), pp. 54-63.

65 SHUTT, T.E. and GRAY, M.W. (2006), Bacteriophage origins of mitochondrial replication and transcription proteins, Trends in Genetics, 22 (2), pp. 92-95. 
«egoísta», según la cual, estas moléculas habrían aparecido al azar en la célula eucariota y su presencia en los virus estaría justificada porque éstos las habrían «secuestrado», «imitado» o «saboteado» ${ }^{66}$. Merecería la pena detenerse a pensar sobre hechos tan significativos como que la célula es la que «activa» a los virus ${ }^{67}$, que en estado libre son inertes, que dispone de receptores para su penetración, que éstos disponen de un mecanismo de inyección de ADN, que la célula aporta su «maquinaria celular» para la actividad de los virus en su interior y que en los cromosomas eucariotas existen hot spots (puntos donde los virus tienden a insertarse). No resulta absurdo considerar que todo esto sea un proceso natural de incorporación y distribución de información genética en sentido amplio, lo que incluye ADN, ARN y proteínas.

Pero la, cada día más evidente, implicación de los virus en la construcción de la vida no se limita a su «puesta en marcha». Veamos algunas de sus contribuciones a la creación de componentes del genoma fundamentales en la evolución. Los elementos móviles y sus derivados constituyen una proporción de los genomas eucariotas que trataremos de cuantificar posteriormente, pero cuyas actividades son reconocidas como responsables de duplicaciones, transposiciones y deleciones, es decir, de cambios trascendentales en la información genética. La supuesta explicación (más bien, «no explicación») de la existencia de elementos móviles basada en su condición de ADN «egoísta» de origen desconocido y su consideración como precursores de los virus mediante su «invención» de los genes necesarios para fabricar la cápsida ya ha sido discutida y los expertos en virus asumen, cada día con más pruebas, su origen independiente ${ }^{68}$, la presencia de una ingente cantidad y variedad de virus en todos los ecosistemas ${ }^{69}$ incluso asignándolos una condición de «reservorio de genes $\rangle^{70} \mathrm{y}\langle\text { tejedores de genes }\rangle^{71}$. Lo que resulta desconcertante

66 MARKINE-GoriaynOFF, N. et al. (2004), Glycosiltransferases encoded by viruses, Journal of General Virology, 85, pp. 2741-2754.

67 Cohen, J. (2008), HIV Gets By With a Lot of Help From Human Host, Science, 319 (5860), pp. 143-144.

68 ZiLlig \& ARNOLD (1999); WoESE (2002).

69 Williamson, K.E., Wommack, K.E. and Radosevich, M. (2003), Sampling Natural Viral Communities from Soil for Culture-Independent Analyses, Applied and Environmental Microbiology, 69 (11), pp. 6628-6633; Culley, A.I., AndRew S., LANG, A.S. and SutTle, C.A. (2006), Metagenomic Analysis of Coastal RNA Virus Communities, Science, 312 (5781), pp. 1795-1798.

70 Goldenfeld, N. \& Woese, C. (2007), Biology's next revolution, Nature, 445, p. 369.

71 Hamilton, G. (2006), Virology: The gene weavers, Nature, 441, pp. 683-685. 
es que cuando en los artículos sobre su actividad genética se ha planteado la disyuntiva de si los elementos móviles provienen de virus o es a la inversa, ambas alternativas se contemplan como probables $^{72}$, sin definirse por ninguna como si el significado de la una y la otra no fueran abismalmente distintos. Pero si asumimos lo que parece evidente, es decir, que en un sentido genérico, los transposones deriven de virus y los retrotransposones de retrovirus, la contribución de los virus a la construcción de los genomas ha sido, por fuerza, la absolutamente mayoritaria ${ }^{73}$. Repitamos los cálculos: Si hemos de creer los resultados de la secuenciación de la fracción codificante de proteínas, que constituye el 1,5\% del total del Genoma humano, además de 223 genes identificados como de origen bacteriano (aunque posiblemente sean más), hasta el $50 \%$ de sus secuencias están formadas por elementos móviles, por encima del $10 \%$ son virus endógenos y «Mucho del restante ADN único debe también ser derivado de copias de antiguos elementos transponibles que han divergido demasiado para ser reconocibles como tales $\gg{ }^{74}$. En cuanto al restante $98,5 \%$, es decir, la fracción «no codificante», que había permanecido fuera del foco de interés de los genetistas por su consideración de «chatarra» o «basura» gracias a la «aportación» de Richard Dawkins ${ }^{75}$, se ha podido comprobar que no sólo es un componente más de los genomas (que no hay «basura»), sino que es el componente fundamental en la explicación de la variabilidad, la complejidad biológica $^{76}$, en la comprensión de la evolución. Y cada día se descubre una nueva actividad fundamental en los componentes de la supuesta «basura», en este caso, y una vez más, en el control del desarrollo embrionario ${ }^{77}$.

No parece que resulte muy difícil de asumir que los responsables de que exista tal cantidad de secuencias repetidas son los retrotransposones y si hemos de buscar un modo por el que estos, con sus especiales transcriptasas inversas han aparecido en los genomas ${ }^{78}$, llegamos a la conclusión, sorprendente pero coherente con lo visto anteriormente, de que aproximadamente el $99 \%$ de los genomas es de origen viral, es decir, que los genomas de los seres

72 Flawell, A.J. (1999), Long terminal repeat retrotransposons jump between species, Proceedings of the National Academy of Sciences USA, 91 (22), pp. 12211-12212.

73 BRITTEN, R.J. (2004), Coding sequences of functioning human genes derived entirely from mobile element sequences, PNAS, 101 (48), pp. 16825-16830.

74 The Human Genome Sequencing Consortium (2001), Initial sequencing and analysis of the human genome, Nature, 409, pp. 860-921.

75 VON STERNBERG (2002).

76 MATtick, J.S. (2003), Challenging the Dogma: the hidden layer of non-protein-coding RNAs in complex organisms, Bio Essays, 25, pp. 930-935.

77 PRABHKAR et al. (2008).

78 BRITTEN (2004). 
vivos, aunque sería más adecuado hablar de «la información genética», lo que incluye el total de los elementos que la controlan, están constituidos por una agregación de genomas bacterianos y virales.

Si a esta condición de los genomas en sentido amplio le añadimos la inimaginable abundancia y variabilidad de virus (se ha estimado que entre $10 \mathrm{y}$ 25 veces más que bacterias), en los medios marinos y terrestre y sus actividades absolutamente imprescindibles en los ecosistemas ${ }^{79}$, nos encontramos con algo sobre lo que sería conveniente detenernos a pensar: Que «nuestros peores competidores» son en realidad, las unidades básicas de la vida. Que, junto con las bacterias, la han fundado y que la vida se sigue desarrollando inmersa, interconectada y regulada por un mar de bacterias y virus. Pero también, que, como desgraciadamente hemos podido comprobar, las bacterias y los virus pueden pasar, cuando las circunstancias lo requieren (por ejemplo, si nos empeñamos en ello), de su condición de constructores a la de destructores.

También podría ser conveniente reflexionar sobre unos datos y unos argumentos que nos indican que, posiblemente, su labor no ha terminado, porque sería no sólo un hallazgo apasionante para la Ciencia, sino también una esperanza para la vida sobre la Tierra. Recientemente, en un artículo publicado en la revista Nature, titulado Biology next revolution, Nigel Goldenfeld y Carl Woese, dos de los mayores expertos mundiales en virus, no informan de que

«la imagen emergente de los microbios como colectivos intercambiadores de genes demanda una revisión de conceptos como organismo, especie y la misma evolución. (...) Igualmente apasionante es la comprensión de que los virus tienen un papel fundamental en la biosfera, en un sentido evolutivo tanto a largo como a corto plazo. Recientes trabajos sugieren que los virus son un importante almacén y memoria de información genética de una comunidad, contribuyendo a la dinámica y estabilidad evolutivas del sistema. (...) Por lo tanto, consideramos lamentable la concatenación convencional del nombre de Darwin con la evolución, porque deben ser consideradas otras modalidades $\rangle^{80}$.

El artículo de una página perdido en el mar de confusión que forman los «descubrimientos» de aplicaciones de elementos móviles y virus para ingeniería genética es sólo una muestra más de la larga lista de artículos y descubrimientos de gran trascendencia ignorados o sepultados por el arrollador avance de la «biología de mercado».

79 Williamson et al. (2003); Suttle, C.A. (2005), Viruses in the sea, Nature, 437, pp. $356-361$.

80 Goldenfeld \& Woese (2007). 
Ahora, una breve puntualización: La denominación de la propuesta como «Integración de sistemas complejos», deriva de la observación de que estas características de los componentes básicos de la vida, cuya aparición en la Tierra de forma gradual es materialmente inexplicable, y la forma en que se integran sucesivamente en entidades de mayor nivel de complejidad, se pueden enmarcar dentro de la Teoría General de Sistemas ${ }^{81}$ : Según ésta, un sistema se define como un conjunto organizado de partes interactuantes e interdependientes que se relacionan formando un todo unitario y complejo. Entre los distintos tipos de sistemas, los seres vivos se ajustan a las características de los llamados "sistemas organísmicos u homeostáticos" (capaces de ajustarse a los cambios externos e internos) y están organizados en subsistemas que conforman un sistema de rango mayor (macrosistema). Los sistemas complejos adaptativos son muy estables y no son susceptibles a cambios en su organización, pero ante un desequilibrio suficientemente grave, su respuesta es binaria: un colapso (derrumbe) catastrófico o un salto en el nivel de complejidad (debido a su tendencia a generar patrones de comportamiento global). Es decir: adaptación (ajuste al entorno) y evolución (cambio de organización) constituyen procesos diferentes. Se podría decir, pues, que existe un modelo teórico, un marco conceptual en el que inscribir la propuesta, pero considero que en el caso que nos ocupa y dada la situación por la que atravesamos, resulta más apremiante la comprensión de fenómenos concretos a partir de datos empíricos que la elaboración de un modelo teórico abstracto y general, por lo que la denominación citada y su adecuación resulta irrelevante para el problema que nos ocupa.

Llegados aquí, tal vez sea conveniente una mirada sobre un supuesto «punto débil» de esta explicación del origen de la vida en la Terra. La idea de que la vida en la Tierra proviene de «semillas» diseminadas por el Universo se puede remontar (al menos, en la cultura occidental) a la Grecia clásica, y el filósofo Anaxágoras ya hablaba de ello. Como ya hemos mencionado, fue el químico sueco Arrhenius el que acuñó el término «panspermia» en 1908 para denominar este fenómeno, retomado posteriormente por el astrónomo galés Alfred Hoyle ${ }^{82}$. Esta hipótesis ha sido rechazada fervientemente por los más prestigiosos teóricos del darwinismo mediante dos argumentos: que sólo cambia el problema de lugar y que el origen de la vida en la Tierra «ya está explicado». En cuanto al segundo, no merece la pena insistir en que está «ex-

81 Von Bertalanffy, K.L. (1968), General System theory: Foundations, Development, Applications, New York, George Braziller, (revised edition 1976).

82 Hoyle, A. (1982), Evolution from space, University College Cardiff Press. 
plicado» de forma gradual y al azar, mediante hipótesis inventadas y si ningún soporte empírico (es más, los datos reales indican su imposibilidad). En cuanto al primero, sí creo conveniente reiterar que lo que cambia es el problema, porque es totalmente diferente el significado (y las consecuencias) de que la vida sea un fenómeno fortuito, de una extremada improbabilidad y único en la Tierra (además de resultar de un «universocentrismo» penoso), a que la vida sea un fenómeno inherente al Universo, que sea una propiedad más (aunque muy especial) de la materia como puedan ser los metales o los gases, cuyas interacciones moleculares tienen sus propias reglas («leyes», en la terminología convencional), y que la vida «germine» allí donde las condiciones son adecuadas a sus características.

$\mathrm{El}$ argumento de que si no podemos precisar cuando y donde se formaron los componentes de la vida por primera vez (que, insisto, al parecer, «ya está explicado»), la hipótesis pierde credibilidad es, por decirlo de un modo suave, inconsistente, porque, como siempre ha pasado en la Ciencia, las explicaciones nunca son completas. Son aproximaciones al conocimiento de los fenómenos que se estudian y siempre hay que reservar, como dice Mauricio Abda$11 a^{83}$, «un extra de humildad» para reconocer que no podemos saber «todo»y esperar que nuevos descubrimientos (posiblemente sorprendentes) o nuevos instrumentos nos permitan avanzar en el conocimiento. En cualquier caso, también es posible que nunca lleguemos a saber exactamente cuando y dónde se formó la vida, pero tenemos datos reales de su primera manifestación sobre la Tierra. Disponemos de observaciones y de conocimientos de procesos verificables experimentalmente que nos permitirán devolver a la Biología a su condición de Ciencia. De construir una base teórica sustentada en hechos reales que se ajuste realmente a lo sucedido en nuestro planeta desde su origen. De comprender que las propiedades de los seres vivos, de su proceso evolutivo y de sus relaciones actuales entre sí y con el entorno, dependen de las propiedades de sus componentes. Si las propiedades de los metales, de los gases, de los líquidos dependen de interacciones atómicas y moleculares concretas, verificables, ¿cómo se puede decir que las de los seres vivos, que comparten con ellos las leyes de la física, la química y las matemáticas, pero que, además, son capaces de «autoorganizarse» y «autogenerarse», y responder coherentemente a los estímulos del ambiente dependen del «azar»? Esto no hace sino convertir al la Biología en una disciplina no susceptible de estudio científico, aunque, como sabemos sí de manipulación (es decir, del llamado «tiro a boleo»). Porque la concepción de la vida como un fenómeno producido «al azar» tiene mucho de

83 AbDalla (2006). 
justificación para perderle el respeto que se merece. Para «someterla a esclavitud». Para destruirla sin haberla llegado a comprender.

\section{LA TRANSFORMACIÓN DE LA EVOLUCIÓN}

El método científico convencional, con sus limitaciones, que son mayores cuanto más complejo es el fenómeno estudiado, consiste en llevar a cabo observaciones empíricas y formular hipótesis que consigan interrelacionarlas por nexos demostrativos, es decir, de una forma verificable. Es decir, no forma parte de la Ciencia explicar realidades en base a proposiciones que se encuentran fuera de los límites empíricos, porque a lo que conduce esta actitud es a pretender explicar continuamente «porqué no vemos lo que deberíamos ver».

Limitémonos, pues, a los datos empíricos y veamos, de una forma necesariamente superficial, de qué forma pueden estar interconectados.

Lo datos que se pueden considerar el punto de partida para comprender la evolución de la vida y la prueba de que esta ha cambiado con el tiempo, son los procedentes del estudio del registro fósil. Los conocimientos, cada día más profundos rigurosos y abundantes, sobre las formas de vida en los diferentes estratos geológicos no han llevado a disponer de una visión, si bien no «completa», sí representativa ${ }^{84}$ de los fenómenos evolutivos. La presencia de procariotas en la Era Arcaica, cuando la Tierra aún no se había acabado de formar, es un hecho verificable. También, que en Paleoproterozoico, hace unos 1600 millones de años, ya existían las eucariotas y que, a partir de su existencia, las «apariciones» en el registro fósil de los organismos multicelulares, primero en el período Vendiano y, posteriormente, y sin conexión directa evidente, en el Cámbrico, se han producido de una manera, poco menos que «repentina» ${ }^{85}$. (Haremos referencia, en este caso, sólo a la evolución animal. Para una revisión de la evolución vegetal ${ }^{86}$ ). A partir de estos estratos, lo que se observa realmente son grandes cambios de organización y aparición súbita de nuevas morfologías coincidiendo, de una forma más o menos ajustada, con los comienzos de los distintos períodos geológicos, a los que han

84 Benton, M.J., Wills, M.A. \& Hitchin, R. (2000), Quality of the fossil record through time, Nature, 403, pp. 535-537.

85 Morris, S.C. (2000), The Cambrian "explosion": Slow-fuse or megatonnage?, Proc. Natl. Acad. Sci. USA, 97 (9), pp. 4426-4429.

86 Moreno, M. (2002), Botánica y evolución, Arbor, 677, pp. 59-99. 
dado nombre sus faunas distintivas ${ }^{87}$. En los estratos correspondientes a cada período se puede comprobar la existencia de cambios menores de organización así como posibles especiaciones sin cambios morfológicos significativos y siempre siguiendo la pauta de los «equilibrios puntuados» ${ }^{88}$, es decir, cambios bruscos y permanencia en «estasis» durante períodos variables, pero prolongados.

Veamos, ahora, evidencias experimentales que nos pueden explicar estas observaciones. Hace tiempo que para los expertos en embriología era evidente que las características del desarrollo embrionario como un sistema jerarquizado e interconectado hacía imposible que los cambios de organización se produjeran mediante la acumulación de pequeños cambios en caracteres superficiales ${ }^{89}$, pero ahora son observaciones empíricas las que dan la razón a estos argumentos: La forma en que los complejos Homeóticos controlan simultáneamente distintos aspectos interrelacionados durante el desarrollo embrionario nos explican complejos cambios de organización difícilmente explicables como sucesos independientes, por ejemplo, el control simultáneo del sistema urogenital y las extremidades necesario para el paso del medio marino al terrestre ${ }^{90}$, o la transición de la organización miriápodo a exápodo ${ }^{91}$. Las investigaciones en el reciente campo de la evo-devo (evolución y desarrollo) arrojan datos, cada día más significativos en este aspecto ${ }^{92}$, pero quisiera destacar unos de un interés especial, porque representa lo que puede ser la aproximación experimental más ajustada a las observaciones del registro fósil: en el artículo Gene regulatory networks and the evolution of animal body plans $^{93}$ se nos informa de la existencia de tres tipos fundamentales de «redes»

87 Schindewolf, O. (1993), Basic Questions in Paleontology: Geologic Time, Organic Evolution and Biologycal Systematics, University of Chicago Press; KEMP, T.S. (1999), Fossils and Evolution, Oxford University Press.

88 Williamson, P.G. (1983), Speciation in molluscs from Turkana Basin, Nature, 302, pp. 659-663.; KerR, R.A. (1995), Did Darwin get it All Right?, Science, 267, p. 1421-1422.

89 Devillers, Ch. and Charline, J. (1993), Evolution. An Evolving Theory, Berlín/Heidelberg, Springer/Verlag; GilberT, S.F., OPITZ, J.M. \& RAFF, R.A. (1996), Resynthesizing Evolutionary and Developmental Biology, Developmental Biology, 173, pp. 357-372.

90 Kondo, T., ZaKauY, J., InNiS, J.W. \& Duboule, D. (1997), Of fingers, toes and penises, Nature. 390, p. 29.

91 Ronshaugen, M., McGinnis, N. \& McGinnis, W. (2002), Hox protein mutation and macroevolution of the insect body plan, Nature, 415, pp. 914-917..

92 HALL (2003).

93 Davidson, E.H. and ERwin, D.H. (2006), Gene Regulatory Networks and the Evolution of Animal Body Plans, Science, 311 (5762), pp. 796-800. 
en el control del desarrollo embrionario: la primera constituye lo que los autores denominan kernels (semillas) que controlan las características de la morfogénesis a nivel de Phylum o Superphylum, el segundo, controla la elaboración de patrones morfológicos, y las alteraciones en distintos niveles el despliegue de sus conexiones y el funcionamiento de sus «interruptores» origina cambios de Clase, Orden y Familia, y finalmente, las alteraciones en baterías de genes y su despliegue serían las responsables de la especiación. Esto nos lleva a recordar la famosa polémica levantada por la honesta afirmación de R. Goldschmidt ${ }^{94}$, derivada de sus observaciones, sobre la necesidad de que los cambios necesarios para que se produjese la especiación habrían de ser, necesariamente, mediante «macromutaciones» de efecto instantáneo con consecuencias visibles sobre la variabilidad de los individuos. La reacción de sus colegas «ortodoxos» fue cruel, calificando burlonamente a los resultados de tales cambios «monstruos sin esperanza» o «monstruos esperanzados». Sin embargo, estos datos reales nos obligan a buscar un proceso también real, existente, que relacione estas observaciones con las procedentes del registro fósil.

Como hemos visto, los conocimientos sobre las complejas características de la información genética y la composición y origen de los genomas nos hablan de la imposibilidad de que estas complejas redes de información puedan cambiar de un modo gradual (y menos «al azar»). Esto implica la necesidad de la existencia de algún proceso que haga posible que nuevas características, a su vez, de gran complejidad y necesariamente interrelacionadas, se incorporen a las anteriores redes de información. Veamos un ejemplo como ilustración de estos argumentos: la transición de la organización reptil a la de mamífero requiere, en el desarrollo embrionario, la incorporación de gran cantidad de características «nuevas» que están estrechamente interrelacionadas entre sí (las unas sin las otras no tendrían sentido). La existencia de un retrovirus endógeno, denominado ERV-3, implicado en la morfogénesis de la placenta $^{95}$, en la formación del sincitiotrofoblasto ${ }^{96} \mathrm{y}$ en la inmunodepresión materna ${ }^{97}$ nos informa (entre otras cosas que veremos más adelante) de la

94 GoldsCHMidT, E. (1940), The material basis of evolution, Yale University Press.

95 Mi, S., LeE, X., LI, X.P., Veldman, G.M. et al. (2000), Syncytin is a captive retroviral envelope protein involved in human placental morphogenesis, Nature, 403, pp. 785-789.

96 Venables, P.J., Brookes, S.M., Griffiths, D., Weiss, R.A., BoYD, M.T. (1995), Abundance of an endogenous retroviral envelope protein in placental trophoblast suggests a biological function, Virology, 211, pp. 589-592.; MuIR, A., LEVER, A. \& MOFFETT, A. (2004), Expression and functions of human endogenous retrovirus in the placenta: an update, Placenta, 25 (A), pp. 16-25.

97 HARRIS, J.R. (1998), Placental endogenous retrovirus (ERV): Structural, functional and evolutionary significance, BioEssays, 20, pp. 307-316. 
existencia de un proceso por el que estas nuevas características se pueden «integrar» en la red genética previa en forma de «subsistema», como parte de un proceso de cambio de organización que, necesariamente, ha de tener otros componentes. Los datos sobre la «incorporación» de nuevas secuencias relacionados con cambios trascendentales en la evolución son cada día más abundantes $^{98}$. También las relacionadas translocaciones y reorganizaciones genómicas relacionadas con los transposones ${ }^{99}$ y con repeticiones de secuencias génicas, parciales o «extensivas» ${ }^{100}$, de evidente origen en los retrotransposones y también originarias de las sucesivas duplicaciones de los genes Hox ${ }^{101}$.

Por lo tanto, tememos una explicación de cómo se pueden producir, de un modo simultáneo y en un gran número de individuos, los «monstruos esperanzados»»: mediante la integración de virus en los genomas. En lo que respecta a cómo las remodelaciones y duplicaciones genómicas se pueden producir simultáneamente en un número suficiente de individuos para que la población resultante sea viable, numerosos estudios han mostrado experimentalmente, mediante la activación por provocación de distintas formas de estrés ambiental (radiaciones, excesos o defectos de determinados nutrientes, sustancias químicas...), la existencia de lo que se denomina hot spots, es decir puntos de los genomas donde tienden a insertarse con más frecuencia los elementos móviles o a producirse las duplicaciones ${ }^{102}$. Lo que hace pensar que, en condiciones naturales, esta frecuencia puede ser aún mayor. Esto a llevado a los citados autores a considerar la existencia de «una variabilidad predeterminada» en la organización animal, es decir, los cambios estarían condicionados o limitados por algún tipo de reglas («leyes», en la terminología convencional). Incluso, podemos disponer de nuevos datos que nos hablan de algunas otras de las «regularidades» que buscába-

98 Pierce, S.K., Massey, S.E., Hanten, J.J. \& Curtis, N.E. (2003), Horizontal Transfer of Functional Nuclear Genes Between Multicellular Organisms, Biological Bulletin, 204, pp. 237-240.

99 LÖNNIG, W.W. \& SAedler, H. (2003), Chromosome Rearrangements and Transposable Elements, Annual Reviews of Genetics, 36 (1), pp. 389-416.

${ }^{100}$ GU, X., WANG, Y. \& GU, J. (2002), Age distribution of human gene families shows significant roles of both large and small-scale duplications in vertebrate evolution, Nature Genetics, 32 (2), pp. 205-209.; MCLYSAGHT, A., HoKAMP, K. \& WolfE, K.H. (2002), Extensive genomic duplication during early chordate evolution, Nature Genetics, 31 (2), pp. 200-204.

101 Wagner, G.P., Amemiya, C. \& Ruddle, F. (2003), Hox cluster duplications and the opportunity for evolutionary novelties, PNAS, 100 (25), pp. 14603-14606.; GARCíAFERNÀNDEZ, J. (2005), The genesis and evolution of homeobox gene clusters, Nature Reviews Genetics, 6, pp. 881-892.

102 LÖNNIG \& SAEDLER (2003). 
mos: recientemente ${ }^{103}$ se ha podido conocer una pista sobre cuando los virus «deciden», en la terminología de los autores, cuando se integran en el cromosoma (fase «lisogénica») o cuando destruyen la célula (fase «lítica»). En un estudio realizado en fagos, han podido comprobar que la tendencia a utilizar la maquinaria celular para hacer copias de sí mismos, lo que acaba por destruir la célula, se produce cuando es un solo virus el que «infecta» la célula. La integración tiene lugar cuando son varios los virus que penetran.

Se podría decir que sólo nos falta una conexión para integrar todos estos datos con las observaciones del registro fósil: Los factores desencadenantes de estos procesos. Y también los hay. Como es conocido, a lo largo de la existencia de la vida en la Tierra, se han producido grandes extinciones asociadas a catástrofes ambientales de dimensiones variables y seguidas de grandes «radiaciones» de nuevas morfologías ${ }^{104}$. Para ilustrar las consecuencias de estos fenómenos, vamos a referirnos al más reciente porque es del que disponemos de una información más clara y abundante y citaremos, una vez más, la honesta descripción de la observación del registro fósil por parte de un científico prestigioso y nada sospechoso de heterodoxia como George Gaylord Simpson:

«El mas asombroso acontecimiento en la historia de la vida sobre la Tierra, es el cambio que ocurrió del Mesozoico, edad de los reptiles, a la edad de los mamíferos. Parece como si el telón hubiese caído repentinamente sobre un escenario en el que todos los papeles habían sido desempeñados por los reptiles, especialmente los dinosaurios, en un número enorme y con una variedad sorprendente, y se hubiese vuelto a levantar inmediatamente para poner de manifiesto idéntica escenografía, pero con un reparto enteramente distinto» ${ }^{105}$.

La catástrofe ecológica producida por la caída de un gran meteorito ha sido suficientemente constatada. Pero hay más. Coincidiendo con esa catástrofe, se produjo una inversión de los polos magnéticos terrestres ${ }^{106}$ que dejó a la

${ }^{103}$ Weitz, J.S., Mileyko, Y., Joh, R.J. and Voit, E.O. (2008), Collective Decision Making in Bacterial Viruses, Biophysical Journal, 95, pp. 2673-2680.

104 KeMP (1999).

105 Simpson, G.G., Pittendrigh, C.S. and Tiffany, L.S. (1957), Life: An Introduction to Biology, New York, Harcourt, Brace.

106 ERICKSON, J. (1992), La extinción de las especies, McGraw-Hill.; Mazur, S., ScheCK-Wenderoth, M. \& KrZYwiec, P. (2005), Different modes of the Late CretaceousEarly Tertiary inversion in the North German and Polish basins, International Journal of Earth Sciences, 94 (5-6), pp. 782-798. 
Tierra sometida a un intenso bombardeo de radiaciones solares. No parece necesario insistir sobre las condiciones que activan, tanto las movilizaciones de los elementos móviles, como las de los virus endógenos. El resultado es un fenómeno que desafía nuestra capacidad de imaginación, pero que se ajusta, que puede explicar, de una forma apoyada en datos existentes, las observaciones reales del registro fósil.

Parece necesario que los biólogos nos desprendamos de concepciones que pudiéramos denominar «populares» (como se «ve» en los dibujos animados) que han dominado la idea de la evolución. Entre otras cosas, porque no son biológicamente, es decir, en base a los procesos que conocemos, posibles. Tenemos que tomar conciencia de la enorme complejidad global del fenómeno que pretendemos estudiar científicamente. Si tenemos en cuenta los largos períodos de estasis por los que pasan las especies, es absurdo pretender que en un período geológico tan corto como el que representa el Paleoceno temprano, los mamíferos terrestres hayan vuelto al mar hasta convertirse, gradualmente, al azar y tras períodos de «estasis» más o menos largos, en ballenas y delfines, porque no hay tiempo para todo esto. Las morfologías animales no varían al azar, porque hay unos complejos de información genética llamados Homeoboxes que las controlan y hay procesos que explican la transición (la transformación) a la organización mamífero. Es decir, los cambios en los ecosistemas, por difíciles de «visualizar» que nos resulten (incluido el que esto escribe) son, como se ha observado en el registro fósil ${ }^{107}$, globales y simultáneos. También lo son, a menor escala, los cambios menores, como las especiaciones ${ }^{108}$, producidos por estímulos de menor repercusión.

En definitiva, hemos de asumir que la acumulación de información sobre los fenómenos biológicos nos sitúa frente a una Naturaleza infinitamente más bella, poderosa y coherente que la sórdida visión que nos «enseñó» la vieja mentalidad simplista, reduccionista, aleatoria y competitiva. Que la vida se desarrolla en medio de unas continuas y estrechas interacciones de los organismos entre sí y con el entorno, mediante el intercambio de información genética por transferencia horizontal de genes, para la cual también existen hot spots, es decir, tendencias predeterminadas ${ }^{109}$, y mediante procesos de ajuste al entorno que producen

107 Eldredge, N. (1997), Síntesis inacabada, Méjico, Fondo de cultura económica.; BEARD, C. (2002), East of Eden at the Paleocene/Eocene Boundary, Science, 295 (5562), pp. 2028-2029.

108 WiLLIAMSON (1983); KERR (1995).

109 Timakov, B., Liu, X., Turgut, I. \& Zhang, P. (2002), Timing and Targeting of $P$ Element Local Transposition in the Male Germline Cells of Drosophila melanogaster, Gene- 
una adaptaciones de una coherencia y eficacia extraordinarias. Que la vida se puede estudiar científicamente, que incluso se puede comprender. Y quizás así lleguemos a ser conscientes de que la Naturaleza es infinitamente más poderosa que nosotros. Que jamás la conseguiremos doblegar ni vivir al margen de ella.

Pero también tenemos que detenernos a pensar sobre otra realidad que la Naturaleza ha puesto ante nuestros ojos. Vivimos literalmente inmersos en un mar de bacterias y virus. Sólo es necesario que consigamos provocar una catástrofe de suficientes dimensiones para desencadenar el siguiente paso.

\section{CONSIDERACIONES FINALES}

La posibilidad de provocar una catástrofe de dimensiones imprevisibles por la manipulación de fenómenos no bien conocidos ni interpretados y sin capacidad de controlarlos realmente no es sólo una (terrible) conjetura. Lo planteamientos reduccionistas (antiguos) en que se basan esas manipulaciones están totalmente al margen de los conocimientos actuales. A la luz de la indescifrable complejidad con que se manifiesta la información genética, de la supeditación de ésta a las condiciones ambientales, de las actividades tan precisas, tan concretas de los virus... no tienen sentido las enormes «inversiones» destinadas por la industria farmacéutica a la búsqueda de «genes de interés comercial», a la obtención de «patentes» para moléculas que, supuestamente controlan procesos complejos y multifactoriales. $\mathrm{Ni}$ el uso de virus, supuestamente «inactivados» para introducir, al azar, genes foráneos en los organismos, como el intento de producir cerdos transgénicos en los que se expresen inmunoglobulinas humanas con el fin de evitar el natural «rechazo hiperagudo» en «el futuro negocio», según The Wall Sreet Journal, de los xenotransplantes.

Ya hemos tenido indicios suficientes de estos peligros. La producción de L-triptófano (usado como suplemento dietético) mediante bacterias modificadas genéticamente produjo, en Estados Unidos, la muerte de 37 personas y mas de 1500 con daños permanentes, la muerte de pacientes sometidos a experimentos de terapia génica o el supuesto «contagio» de SIDA, de un paciente sometido a estos experimentos, deberían hacer pensar en el sentido y el peligro real de semejantes intentos. Y aquí me voy a atrever a someter al cri-

tics, 160, pp. 1011-1022.; Medrano-Soto, A., Moreno-Hagelsieb, G., Vinuesa, P., Christen, J.A. \& Collado-VIDES, J. (2004), Sucessful Lateral Transfer Requires Codon Usage Compatibility Between Foreign Genes and Recipient Genomes, Moleculat Biology and Evolution, 21(10), pp. 1884-1899. 
terio del lector una información sobre un terrible indicio de estos peligros: Desde 1992 hasta 1999, el periodista Edward Hooper siguió el rastro de la aparición del SIDA hasta un laboratorio en Stanleyville en el interior del Congo, por entonces belga, en el que un equipo dirigido por el Dr. Hilary Koprowski, elaboró una vacuna contra la polio utilizando como sustrato riñones de chimpancé y macaco. El «ensayo» de esta vacuna activa tuvo lugar entre 1957 y 1960, mediante un método muy habitual «en aquellos tiempos», la vacunación de más de un millón de niños en diversas «colonias» de la zona. Hooper fue vapuleado públicamente por una comisión de científicos que negaron rotundamente esa relación. Desde entonces, se han publicado varios «rigurosos» estudios que asociaban el origen del sida con mercados africanos en los que era práctica habitual la venta de carne de mono o, más recientemente, «retrasando» la fecha de aparición hasta el siglo XIX mediante un supuesto «reloj molecular» basado en la comparación de cambios en las secuencias genéticas de virus. Lo que Hooper ni Koprowsky podían saber era que los mamíferos tenemos virus endógenos que se expresan en los linfocitos y que son responsables de la inmunodepresión materna durante el embarazo.

Las barreras de especie son un obstáculo natural para evitar el salto de virus de una especie a otra. Son necesarias unas condiciones extremas de estrés ambiental o unas manipulaciones totalmente antinaturales para que esto ocurra. Como, por ejemplo, que se consiguiera superar el «rechazo hiperagudo» en los xenotransplantes y que, con la supervivencia del paciente, se crearan las condiciones para la hibridación de nuevos virus incontrolables...

Es necesario detenerse a pensar sobre lo que hay realmente detrás de muchas supuestas soluciones a problemas inexistentes o mal diagnosticados, como la puesta en el mercado de millones de dosis de supuestas vacunas contra la «gripe aviar», o las campañas de vacunación masiva contra un virus endógeno. Porque, como todos sabemos, «el Mercado» es el que dirige el destino de la Humanidad. Y ante «el Mercado», ni la ética, ni la Ciencia, ni la verdad, tienen ningún poder.

Los biólogos, los científicos, tenemos ante nosotros una grave responsabilidad: Decidir si asistimos pasivamente al desenlace de esta aventura irresponsable, o si afrontamos la tarea de construir y transmitir a la sociedad una Biología realmente científica. Al servicio de la Humanidad.

Fecha de recepción: 15 de octubre de 2008

Fecha de aceptación: 15 de julio de 2009 